\title{
Detection of significant changes in short time series: applications to the analysis of annual routines in behavioural ecology and to the analysis of breaks in abundance
}

\author{
$\underline{\text { N. Bru }}^{\text {a }}$, E. Biritxinaga ${ }^{\text {a }}$ and F. D'Amico ${ }^{b}$ \\ ${ }^{a}$ Laboratoire de Mathématiques et de leurs Applications de Pau UMR CNRS 5142- University of Pau et des \\ Pays de l'Adour-France ; ${ }^{b}$ UMR Ecobiop INRA-UPPA, Campus Montaury, University of Pau et des Pays \\ de l'Adour-France \\ Email:noelle.bru@univ-pau.fr
}

\begin{abstract}
The aim of this paper is to identify significant changes, otherwise known as change-points, in short time series. The practical application that motivated this work concerns the detection of change-point differences in behavioural annual routines of living organisms (i.e. how they schedule activities in a regular way over the year). Our study case focuses on the annual routine of a specialist river bird species, the European Dipper (Cinclus cinclus), coping with drastic environmental changes in flow regime impacting their life-history stages. We compare behavioural data collected on a monthly basis in natural and altered rivers; they result in 12 values of so-called time-activity budgets expressed as mean percentage of time spent in each of 5 different behavioural activities. The methods used in this paper are based on statistical tests for detecting one or more points of breaks in time series. Different methods are compared on this first dataset :
\end{abstract}

- The method of A. N. Pettitt (1979) which is based on the Mann and Whitney statistical test for comparing two samples thus 2 segmentations of the original time series;

- $\quad$ The method of P. Hubert et al. (1989) for which the test statistic considers the squared difference between the series and a fixed segmentation. In this algorithm all possible segmentations of a time series are tested and the optimal segmentation is selected using the method of contrasts introduced by Scheffe (1959);

- $\quad$ The method developed recently by L. Bordes et al. (2010) whose statistics do not depend on parametric assumptions on the distribution of the data. The thresholds of statistical inference in this paper are determined by a Monte Carlo method.

Most of these methods were developed and used on long time series of statistical index (including hydrology and climatology applications). Thus, they have to be adapted to the study of phenomena on short duration, i.e. small samples size through resampling techniques. In addition, to take into account the dependence between successive observations induced by the fact that they are time series, bootstrapping techniques for dependent data are implemented to adjust statistical inference (due to the specific nature of the data).

The irrespective interest of these methods is demonstrated on the studied original dataset (i.e. the Dipper behavioural annual routine). It is shown that significant differences in annual routine exist for 3 of the 5 behavioural categories between the two contrasting environments (natural vs altered flow regime), thus mathematically confirming the biological predictions made independently.

We also present another application of these methods to historical time series (about 30 years) of annual abundance of European Eel in France. The advantage of this kind of application is to determine potential dates of any sudden change of abundance and to link them to external phenomena where significant decrease/increase occurs, such as accidental pollutions, immediate effect of regulatory management, disease outbreak, and more generally to any field of ecology where analysis of change-point along annual routine is necessary.

Keywords: change-points, time dependent data, segmentation, Cinclus cinclus, Anguilla anguilla, block bootstrap, Monte Carlo method. 


\section{INTRODUCTION}

The management of ecosystems requires the collection of data to define one or more quantitative indicators whose evolution is typically observed year by year, or month by month (within a year). Today, most of these information systems exist (combining biological resources, socio-economic index) on a relatively short period of time and therefore give a vision of the "short term" evolution. The difficulty is thus to appreciate any trend in the dynamical process and/or detect significant changes which would allow to define efficient strategies for ecosystem management or to detect the impact of some human activities on the behaviour of natural ecosystem.

The practical application that initially motivated this work deals with the detection of change-point differences in behavioural annual routines of living organisms (i.e. how they schedule activities in a regular way over the year). By definition, when annual routines are to be analysed on a monthly basis, the data result in a small series limited to 12 values, thus the need for tools for short time series analysis. Our case study focuses on the annual routine of a specialist river bird species, the European Dipper (Cinclus cinclus), coping with drastic environmental changes in flow regime impacting their life-history stages. We compare behavioural data collected on a monthly basis in natural and altered rivers; they result in 12 values of socalled time-activity budgets expressed as mean percentage of time spent in each of 5 different behavioural activities (D’Amico \& Hémery 2007).

This paper is a contribution to the analysis of short time series through the detection of possible breaks in the trend by way of the identification of significant changes, otherwise known as change-points. These breaks are possibly due to some reaction of the ecosystem to external perturbations. We focused on approaches which allow the detection of different mean levels of the time series and therefore non-stationarity.

In addition, to take into account the dependence between successive observations induced by the fact that they are observed over time, bootstrapping techniques for dependent data have been implemented to adjust for statistical inference.

We will also present another application of this method to historical time series (about 10 years) of annual indicators of abundance of European Eel in France. The advantage of this kind of application is to determine potential dates of any sudden change of abundance and to link them to external phenomena when significant decrease/increase occurs (such as accidental pollutions, immediate effect of regulatory management, disease outbreak) and more generally to any field of ecology where analysis of change-point along annual routine is necessary.

\section{BIOLOGICAL AND ECOLOGICAL RATIONALE FOR DETECTION OF SIGNIFICANT CHANGES IN SHORT TIME SERIES}

\subsection{A general framework in aquatic ecosystems}

Freshwater ecosystems provide water, one the most essential resources for today and the future of the planet. However, these ecosystems are increasingly threatened worldwide, impairing biodiversity (Vörösmarty et al. 2010). Threats arise from multiple stressors affecting living organisms through similar indirect or direct pathways (Figure 1).

Indirect effects involve changes in natural flow regime in turn affecting habitat, water quality and resources structure. Temporal fluctuations in natural water flows are particularly important because they are known to shape species life histories over time scales as well as structure the ecological processes and productivity of aquatic and riparian communities (Lytle \& Poff 2004). Natural flow regimes are characterized by several temporal key features: magnitude, frequency, duration, timing, rate of change, and predictability of discharge (Poff et al. 1997). Each of these features is susceptible to affect directly annual routines of organisms (McNamara \& Houston 2008), their behaviour and their energetics (i.e. how they balance their energy budgets and their abundance). Direct effects, such as fishing, play a major role in extirpating aquatic fauna.

Maintaining native biodiversity in streams and sustained fisheries depend on the understanding of how organisms

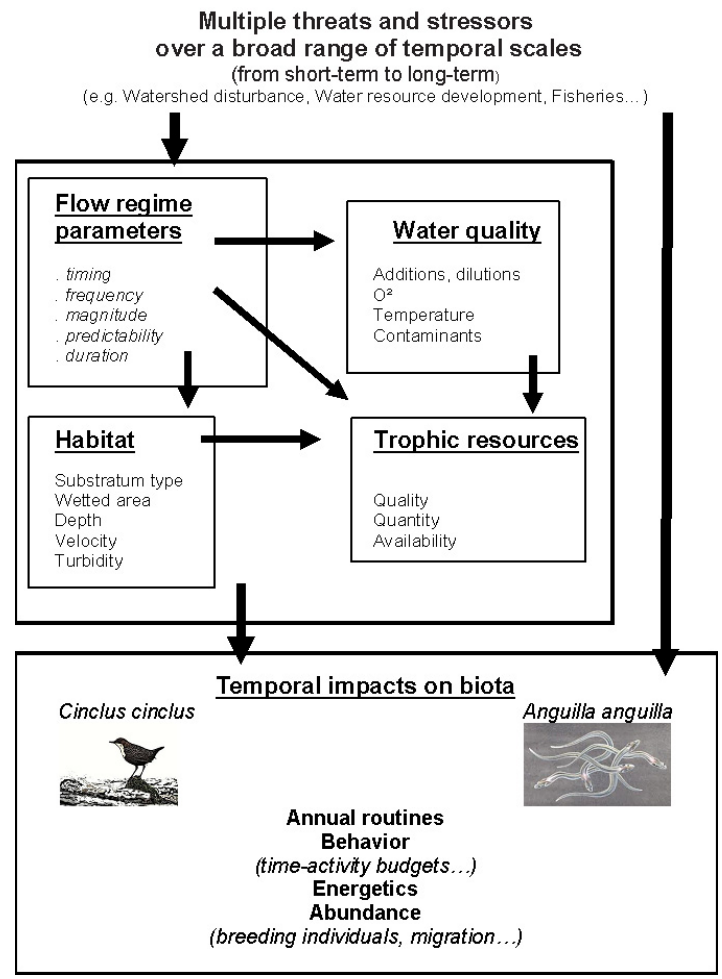

Figure 1. Framework of the study. 
have evolved to depend on and adapt to temporal variations in flow regimes or fishery pressure respectively. Hence this study, in which we examine how selected life-history of two key aquatic species (the European Dipper and the European Eel) may be time-dependent.

2.2. Two worked biological examples: investigating short-term variation in European Dipper (Cinclus cinclus) behaviour along managed rivers and understanding the decline in abundance of European Eel (Anguilla anguilla) in the same watershed.

Among specialist river birds, the European Dipper (Cinclus cinclus) is unique among passerines by its reliance on diving to achieve energy gain in fast-flowing waters to exploit a diverse range of aquatic invertebrates. It is thus considered a good indicator of changes in water quality (Ormerod \& Tyler 1993). Behavioural adaptations enable individual birds to respond directly to temporal variation in flow patterns (one of the assumptions of the Natural Flow Regime Paradigm referred to above - Lyttle \& Poff 2004). Because behaviour of this specialist river bird species is finely tuned to temporal patterns of flow regime, it should be impacted by flow regime alteration, downstream dams for example, where management by hydropeaking waves or compensation flow occur (D'Amico et al. 2000). Behavioural studies were undertaken between 1998 and 2001 along natural (unregulated) and regulated (below dams) segments (see full description in D'Amico \& Hémery 2007) of three tributaries of the upper river Gave d'Ossau (Western Pyrénées) flowing into the Adour river to the sea (Bay of Biscay; France).

The European Eel (Anguilla anguilla) is a species of great economic importance for the west European coast of the Atlantic Ocean and the Mediterranean Sea. It is a strongly declining fish species, prompting urgent management action (ICES 2009). Since 2008, the scientific research project EELIAD (supported by the EUhttp://www.eeliad.com/project.htm) brings some information "to enable management actions to enhance and conserve eel stocks across Europe, and to determine the dynamics of Eel population structure and reproductive success". In addition, these different studies will be linked to studies and observations undertaken in other cooperative projects such as INDICANG which is a network of monitoring programs that report on the status and the development of eel populations over a large area (e.g. Atlantic Area). Its life cycle is amazing and one of the most fascinating ones on earth, starting as a leaf-shaped larva in the Sargasso sea and implying a fascinating trans-Atlantic migration to the freshwater rivers of Europe, where they feed. Adult Eels (yellow and silver stages) are intensively exploited in north European and Mediterranean countries (http://www.eeliad.com/background.htm). The recruits of the species (glass eel and elver stages) are harvested commercially during their mass migration to the continental coast, mainly in the Bay of Biscay (France) and the Bristol Channel (United Kingdom). In France, eels are fished by professional fishermen from the glass eel stage (young eels) till the adult stage (silver eels), that is two kinds of fisheries are concerned. Consequently, the activity of many marine professional fishermen and river ones depends on this resource. The French cooperative project INDICANG has reported on the status of Eel populations in relation with fishing pressure and its environment (Adam et al. 2008). Since 2002-2003, the catches of glass eels in France have declined, as did the number of licenses granted to professional fishermen. The causes of this decline could be: over-fishing, river fragmentation by dams (Laffaille, Caraguel \& Legault 2007); poor environmental quality, resurgence of disabling illness. It is therefore essential for managers to detect levels of alert in the estimates of biomass while considering the socio-economic aspects, including the viability of the fishing activity.

\section{HOW TO DETECT SIGNIFICANT CHANGES IN SHORT TIME SERIES?}

\subsection{Dealing with some change-points}

The methods used in this paper are based on statistical tests (or similar method) for detecting one or more change-points in time series. The aim of the study is to discuss the results obtained by different methods to compare the results in terms of scenarii for biological interpretation. It is by no means to define the best among many in terms of statistical properties even if some indicators of performance are given. In addition, for the sake of interpreting the results, it is necessary to provide the practitioner, in case of change points, the corresponding dates to determine a possible match with the biological assumptions. Thus, methods based on test with maximum-type statistics were preferred to easily obtain the time of change-point. Thus, several approaches are compared on the datasets presented above and discussed using simulations results.

\subsection{Hypothesis tested}

The main hypothesis is whether the dynamics is stable (or stationary) over time or if there are one or more dates at which a structural change in the dynamics of the phenomenon should be seen and interpreted 
by users. So, for this first approach, the selected methods are for detecting change-points on the mean with the minimum number of mathematical conditions often difficult to verify in practice.

In the paper of Lubès-Niel et al. (1998), the question is already asked to compare the power of different methods to determine the homogeneity of time series through Monte- Carlo simulations on a large number of short series of length 50 . They are concerned with the power and robustness of five methods by testing different kinds of time series using iid random variables from different probability distributions, stationary and non-stationary due to a jump on the mean (and/or on the variance) or with a trend. Further results on autocorrelated series (stationary or not) are also given. In the following, two methods mentioned by LubèsNiel et al. (1998) are discussed.

\subsection{An "old" non-parametric approach to detect one change point in time series}

The method of Pettitt (1979) proposes to test for no change-point against one change without hypothesis on the initial distribution. It consists of a series sweep by splitting it into two sub-samples. Comparing the distributions before and after the cut-off time enables finding a possible change-point that allows for significant differences. This method is non-parametric based on the Mann and Whitney statistical test for comparing two independent samples and gives the date of change-point. According to the results of Lubès-Niel et al. (1998), this method performs relatively good power in the case of iid series with a break on the mean but it is very sensitive to the two levels before and after the change-point: the power varying between $16 \%$ and $50 \%$ in their simulations. In the case where some autocorrelation is introduced, the first kind risk depends on the autocorrelation coefficient $\rho$ : between $13 \%$ and $92 \%$ if the series is stationary for $\rho$ varying from 0.2 to 0.9 (less than $1 \%$ if $\rho<0$ ) and between $10 \%$ and $78 \%$ of change-points correctly detected for $\rho$ ranging from -0.9 to 0.9 and several levels of jumps.

\subsection{Considering in addition short time series}

In the case of short times series and moreover dependent values, the level of dependence between the values and the robustness of the method are important factors impacting the decision procedure and the conclusion about the existence of one change-point. Lubès-Niel et al. (1998) argue this fact in their results in the case of Pettitt's test but also for other tests like the rank correlation tests (which do not provide a date for change-point) or the Bayesian method of Lee \& Heghinian (1977) based on the at-most-one-change (AMOC) location modeling which requires normality of the variables.

To avoid the conditions of applications required in the previous method, Antosha \& Hušková (2001) propose, in the same modeling framework, the use of some permutation test to get asymptotically correct approximations for critical values. According to them, this methodology can be extended to the case of multiple changes in location models. This will be investigated into further work.

For the above reasons, we then improve the calculation of the statistic and the threshold value for the decision procedure of finding some change-points using different methods:

- Method 1: The method of Pettitt (1979) using a statistical table giving the release thresholds for inference estimated by a Monte-Carlo procedure.

- Method 2: The method developed recently by Bordes et al. (2010) whose statistics do not depend on parametric assumptions on the distribution of the data. The thresholds for statistical inference in this paper are determined by a Monte Carlo method. The test statistic proposed by Bordes et al. (2010) introducing a normalization through the standard deviation is also considered.

\subsection{Combining short time series and several change-points}

The only method studied in this preliminary work is the one of Hubert et al. (1989). It proceeds step by step: segmentations of different orders are tested using a distance criterion based on the squared differences between the series and a fixed segmentation and the best segmentation is chosen to be effective according to the contrast test of Scheffé (1959). This algorithm results in two steps of inference with two risks: the choice of the order of segmentation and the validation of the segmentation by Scheffé's test which requires an assumption of normality. This method is more efficient to handle long time series according to the underlying mathematical hypothesis. For a risk $\alpha=5 \%$ for the Scheffé's test:

- In the stationary iid case, Hubert et al. (1989) found that in 47\% of the cases $(53 \%$ for Lubès-Niel et al. 1998) at least one change-point is detected.

- In the iid case with one break on the mean, Lubès -Niel et al. (1998) through their simulations show that $60 \%$ of the series are detected as non-stationary when the jump is really strong. However, Lubès-Niel et al. (1998) indicate that the choice of the risk in Scheffé's test greatly influences the performance of the method and therefore, they use the value recommended by Hubert with no real justification: $\alpha=1 \%$. 
- In the stationary autocorrelated case, the proportion of cases where the series is found stationary is $100 \%$ if the autocorrelation coefficient is less than 0.2 and less than $1 \%$ if it is equal to 0.9 .

- In the autocorrelated case with one break on the mean, the proportion of time series well classified is about $60 \%$ when the autocorrelation coefficient is positive and increases with the value of the autocorrelation coefficient. But the results remain sensitive to the level of the break.

\subsection{Final discussion: towards a proposition of a modified Hubert's method}

The main method we are interested in is based on the above segmentation procedure of Hubert et al. (1989) which allows finding several possible change-points in time series while method 1 and 2 are able to detect only a single one. But an adjustment has to be made because this method is sensitive to:

i. The magnitude of the values as shown by the various simulations of Lubès-Niel et al. (1998),

ii. The autocorrelation level if it exists,

iii. The choice of $\alpha$ for Scheffé's test which in addition needs normality and independence.

Some changes are made to avoid these problems and consist in: a distance criterion penalized according to the order of segmentation and the magnitude of the values of the series (point i); the use, in first approach, of a block-bootstrap of arbitrary order 2 to determine the optimal segmentation which allows to take into account a kind of autocorrelation between two successive values. This is how we define what we call method 3 which is studied through 1000 simulations of autocorrelated series of type AR(1) of length 12, with zero mean, standard deviation 1 and autocorrelation $\rho$ : stationary ones or with a change-point in the mean. In both cases, we can see that method 3 detects less change-points (ranging from 0 to 2 change-points) than the one of Hubert et al (ranging from 0 to 4 change-points). In the autocorrelated stationary case,

- with $\rho=0.7$ : method 3 does not detect changes in $35 \%$ of cases ( $26 \%$ for Hubert et al.). Consistency of results between the methods: $67 \%$ between method 3 and Hubert's, $71 \%$ and $63 \%$ respectively with Pettitt's and Bordes' et al. When a change-point is detected in $2.4 \%$ of cases it is an outlier and in $9 \%$ one segment is of length 2 .

- with $\rho=0.2$ : method 3 does not detect a change-point in $74 \%$ of cases, while Hubert's is $60 \%$, Pettitt's $88 \%$ and Bordes' $90 \%$.

In the case of autocorrelated series with a change-point at $\mathrm{t}=6$, a level between the two means equal to $100 \%$ of the standard deviation,

- with $\rho=0.2$ : method 3 detects the change-point in $63 \%$ of cases against $46 \%$ and $32 \%$ for Pettitt's and Bordes' respectively. When a single change-point is detected, it is between the dates 5, 6 and 7 in $59 \%$ of cases while $18 \%$ for Bordes' and $83 \%$ for Pettitt's. When method 3 proposes 2 change-points, one of them is located between dates 5,6 and 7 in $67 \%$ of cases.

- With $\rho=0.7$ : method 3 detects the change-point in $86 \%$ of cases against $78 \%$ and $59 \%$ for Pettitt's and Bordes' respectively. When a single change-point is detected, it is between the dates 5, 6 and 7 in $56 \%$ of cases while $15 \%$ for Bordes' and $88 \%$ for Pettitt's. When method 3 proposes 2 change-points, one of them is located between dates 5,6 and 7 in $52 \%$ of cases.

\section{APPLICATIONS TO WORKED EXAMPLES: MONTHLY DIPPER BEHAVIOURAL DATA AND ANNUAL EEL ABUNDANCE DATA}

In all the following examples, conclusions are made using for testing an error term $\alpha=5 \%$.

\subsection{European Dipper behaviour: influence of contrasting management on time-activity budgets}

Monthly time-activity budgets were described under the same five main headings categorizing individually marked birds activities (see D'Amico \& Hémery 2007): resting coded rest (= time spent stationary during the day including standing quiet and alert, preening, singing, food manipulation and bobbing), foraging coded for (= all walking activity, almost mainly devoted to pacing and pecking while feeding), diving code div (= all subsurface feeding), flying coded fly whilst all other rare activities were gathered into a miscellaneous category (hereafter called other coded oth). This is the representation of a seasonal effect that is supposed to be repeated in the same way year by year if the environmental context does not change significantly. To assess the differences between the same behaviour in natural rivers and regulated rivers, we consider the series of gaps as the difference between behavioural indicators in regulated rivers and the natural ones. Analysis of this series of gaps should allow us to evaluate the differences between the two sites as follows: if the series of differences is stationary during the year (i.e. constant mean), this can mean either the behaviour is identical for the two sites (if this average value is zero) or either the shapes are changing in the same way but differ only on intensity (if the average value is shown to be a non-zero constant). The results are given in Table 1 . 
Table 1. Detection of change-points in behavioural indicators

\begin{tabular}{|c|c|c|c|c|c|c|}
\hline Comparison of methods & For & Div & Res & Fly & Oth & Treshold \\
\hline Method 1 & 17 & 27 & 22 & 15 & 22 & $\mathbf{2 8}$ \\
\hline Method 2 & 4.07 & 2.03 & 4.58 & 4.06 & 2.77 & $\mathbf{5 . 1 2}$ \\
\hline \multirow{2}{*}{ Method 3 } & 4 change-points & 3 change-points & 4 change-points & 4 change-points & 3 change-points & \\
\cline { 2 - 5 } & \multicolumn{7}{|c|}{ identical from March to October } \\
\hline
\end{tabular}
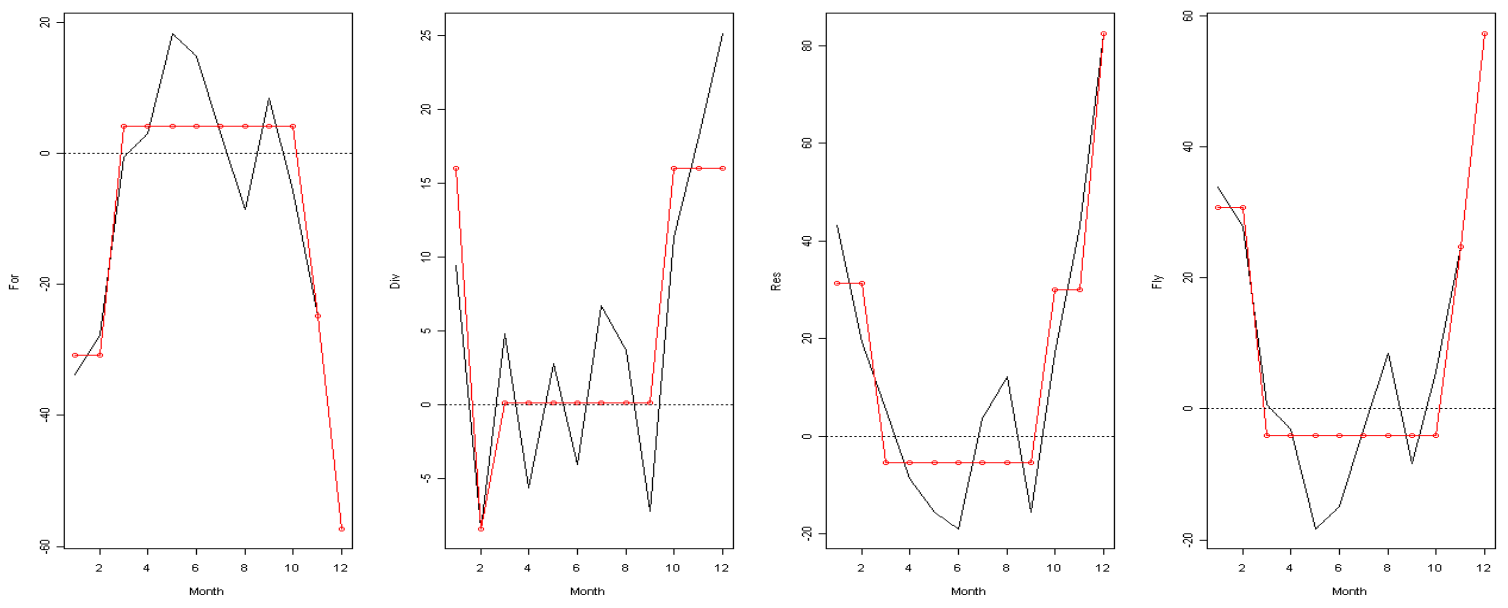

Figure 2. Segmentations obtained on 4 behavior with method $3:-=$ real values, $-=$ segmented means.

Prior to the field survey, biologists thought the two behaviours were not the same along the year. Methods 1 and 2 fail to demonstrate such differences (see Table 1), and the proposed refined approach (Method 3) succeeded in it. So, biological interpretation is straightforward (see Figure 2): behavioural strategies do differ i/ between birds in regulated versus natural rivers and ii/ between periods of the year. The focus is only made on the period of length greater than one because one value can be interpreted as outliers.

\subsection{Glass eel abundance: short-time patterns of global catches and catches related to the number of fishing licences in France}

Information about the glass eel catches data and fisheries were collected for the French territory by the CMEA (Commission for estuarine ecosystem and diadromous fish), CNEPMEM (National Committee for marine fisheries and marine farms) and CONAPPED (National Committee of the freshwater fishing). Informations of annual catches allow to assess two main purposes:

- the dynamics of production of this resource by identifying if the contribution of the fishery increases or not (which can then be associated with the establishment of regulations, the state of the resource, any price changes, et cetera),

- the economic contribution of this species in the fishing industry in France when the biomass is converted to euros (then allows to identify the value of the species and thus leads to the classification of species in the French fishery in terms of economical importance).

The use of catches related to the number of fishing licenses provides a view of the evolution of the average yield per fisherman which must then be linked to the fishing effort and the whole environment of catches...

These two kinds of information were presented in April 2011 to the EELIAD partners during the annual EELIAD meeting and method 3 is applied to detect significant changes (see Figures 3 and 4):

\footnotetext{
${ }^{1}$ For this method, the algorithm was adapted to the fact that the data are supposed to be a cycle so they can repeat identically year by year.
} 


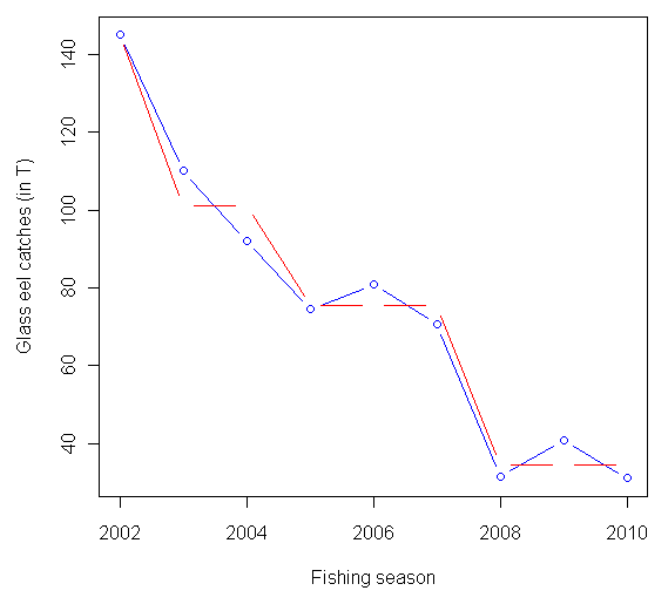

Figure 3. Glass eel catches in France since 2002.

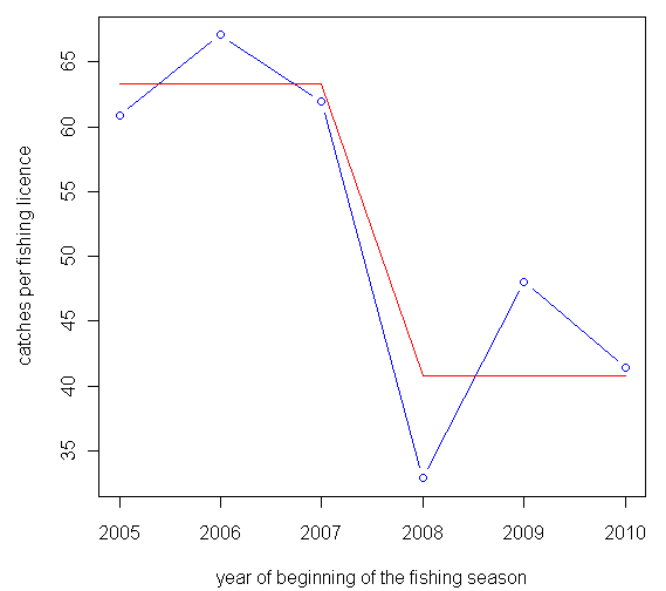

Figure 4. Catches per fishing license since 2005.

The segmentation of the glass eel catches series shows several steps of significantly different levels over time. We also note that these steps are decreasing suggesting that the level of the catches tend to decrease significantly from year to year. In this situation, the shape of the curve for glass eel catches per fishing license over the period 2005-2010 is similar to that of the total catches for the same period and shows the breakpoints on the same dates. The year 2008 is an important date for which the level of the glass eel catches as the yield per fisherman has reached a level significantly lower than the ones previously observed on a short period. These significant changes at a lower level certainly require effective management decisions in the short term to maintain this activity.

\section{DISCUSSION AND CONCLUSIONS}

Pettitt's approach is based on the calculation of rank test, whilst method of Hubert et al. lies on the numerical values of the series of observations. Pettitt (1979) compares the results with a cumulative sums method (CUSUM): the latter is very sensitive to extreme values and therefore the results can be disrupted and lead to erroneous conclusions when only a single change-point is detected. However, as shown by the results on real data with method 3, it may be interesting to highlight some outliers for the practitioner.

The Hubert's modified algorithm proposed in this paper is based on a penalized criterion of distance to discuss the adequacy between the observed values and the proposed segmentation. The term added to penalize the distance measure is inspired by the correction seen in the case of AIC for small samples. Then, to avoid the Scheffé's test, block bootstrap with an arbitrary choice of block size 2 (when possible) is used to estimate the mean of each segment and to find confidence interval used to validate or not the significant differences of means. Politis (2003) proposes a review of bootstrap method for time series. Later, Kirch (2007) and Hušková et al. (2008) consider block permutations to obtain approximations of the critical values of one change-point tests in the framework of the AMOC model or autoregressive time series. No investigations are actually made to use this theory with our applications. As such, method 3 must not be used in the case of time series larger than 20 because the calculation time becomes too long.

The irrespective interest of the method is demonstrated on the studied original dataset (i.e. the Dipper behavioural annual routine). It is shown that significant differences in annual routine exist for the 5 behavioural categories between the two contrasting environments (natural vs altered flow regime), thus mathematically confirming the biological predictions made independently. However, the question remains: which method to believe?

These kinds of methodologies will find immediate applications in behavioural ecology and ecophysiology where analysis of change-point along daily, monthly or annual routine is necessary. More generally, it should prove extremely useful in the fields of ecological and environmental studies where sudden and significant changes in patterns are expected, and where there is an absolute necessity to predict the development of natural ecosystems with and without human impact. 
Bru et al., Detection of significant changes in short time series

\section{REFERENCES}

Adam G., Feunteun E., Prouzet P. \& Rigaud C. (coord) (2008). L'anguille européenne - indicateurs d'abondance et de colonisation. Quae Editions, France.

Antoch J. \& Hušková M. (2001). Permutation tests in change point analysis. Statistics \& Probability Letters, $53 ; 37-46$.

Bordes L., Ibled F., Paroissin C. \& Turlot J.C. (2010). Early detection of change-point in hazard rate with small sample size. http://hal.archives-ouvertes.fr/view by stamp.php (hal-00507452 - version 2)

D’Amico, F., Manel, S., Mouches, C \& Ormerod, S.J. (2000). River birds in regulated rivers: cost or benefit?. Verh. Internat. Verein. Limnol. $27: 167-170$.

D’Amico F. \& Hémery G. (2007). Time-activity budgets and energetics of the annual cycle of Dippers Cinclus cinclus in upland streams are dictated by the pattern of temporal variation in river flow. Comparative Biochemistry and Physiology A, 148, 811-820.

Hubert P., Carbonnel J.P. \& Chaouche A. (1989). Segmentation des séries hydrologiques : applications à des séries de précipitations et débits de l'Afrique de l'ouest. Journal of Hydrology, 110, 349-367.

Hušková M., Kirch C., Prášková Z. \& Steinebach J. (2008). On the detection of changes in autoregressive time series,II. Resampling procedures. Journal of Statistical Planning and Inference, 138, 1697-1721.

ICES 2009. Report of the 2009 session of the Joint EIFAC/ICES Working Group on Eels. CM 2009/ ACOM 15. http://www.ices.dk/reports/ACOM/2009/WGEEL/WGEEL\%20final\%20Report\%202009.pdf

Kirch C. (2007). Block permutation principles for the change analysis of dependent data. Journal of Statistical Planning and Inference, 137, 2453-2474.

Laffaille P., Caraguel J.-M. \& Legault A. (2007). Temporal patterns in the upstream migration of European glass eels (Anguilla anguilla) at the Couesnon estuarine dam . Estuarine, Coastal and Shelf Science, 73(12), 81-90.

Lee A.F.S. \& Heghinian S.M. (1977). A shift of the mean level in a sequence of independent normal random variables : a Bayesian approach. Technometrics, 19(4), 503-506.

Lubès-Niel H., Masson J.M., Paturel J.E. \& Servat E. (1998). Variabilité climatique et Statistiques - Étude par simulation de la puissance et de la robustesse de quelques tests utilises pour vérifier l'homogénéité de chroniques. Rev. Sci. Eau, 3, 383-408.

Lytle D.A. \& Poff N.L. (2004). Adaptation to natural flow regimes. Trends in Ecology \& Evolution, 9, 94100 .

McNamara J. M. \& Houston A. I. (2008). Optimal annual routines: behaviour in the context of physiology and ecology. Phil. Trans. R. Soc. B, 363, 301-319.

Ormerod S.J. \& Tyler S.J. (1993). Birds as indicators of changes in water quality. in : Furness R.W.\& Greenwood J.J.D. (eds.) Birds as Indicators of Environmental Change, 179-216. Chapman and Hall, London.

Pettitt A. N. (1979). A Non-Parametric Approach to the Change-Point Problem. Applied Statistics, 28, 126135.

Poff N.L., Allan J.D., Bain M.B., Karr J.R., Prestegaard K.L., Richter B.D., Sparks R.E. \& Stromberg J.C. (1997). The natural flow regime. BioScience, 47, 769-784.

Politis D.N. (2003). The impact of Bootstrap Methods on Time Series Analysis. Statistical Science, 18(2), 219-230.

Poulsen B., Holm P. \& MacKenzie B. R. (2007). A long-term (1667-1860) perspective on_impacts of fishing and environmental variability on_fisheries for herring, eel, and whitefish in the Limfjord, Denmark. Fisheries Research, 87 (2-3), 181-195.

Scheffe (1959). The Analysis of Variance. John Wiley \& Sons Inc., New York, 447p.

World Water Assessment Programme. Water in a Changing World. The United Nations World Water Development Report 3 (UNESCO, 2009). 